\title{
Preoperative Predictors for Improvement after Surgical Untethering in Occult Tight Filum Terminale Syndrome
}

\author{
Andrew J. Fabiano Mohammed F. Khan Curtis J. Rozzelle Veetai Li \\ Department of Neurosurgery, Women and Children's Hospital of Buffalo, Kaleida Health, School of Medicine and \\ Biomedical Sciences, University at Buffalo, State University of New York, Buffalo, N.Y., USA
}

\section{Key Words}

Occult tight filum terminale syndrome $\cdot$ Spinal cord .

Surgical untethering

\begin{abstract}
Background/Aims: An occult tight filum terminale syndrome has been described wherein clinical symptoms result from tension on the spinal cord despite nondiagnostic spinal magnetic resonance imaging (MRI). Recent reports have suggested a role for surgical untethering in this patient population; however, controversy remains regarding the surgical treatment of this condition. Owing to the various clinical presentations, the relationship of presenting signs and symptoms to postoperative outcomes might be useful in surgical selection. Methods: A retrospective review was conducted of 22 pediatric cases of surgical untethering for suspected occult tight filum terminale syndrome. All patients had nondiagnostic MRI findings, defined as a conus medullaris above the $L_{3}$ vertebral body and a filum terminale diameter of less than $2 \mathrm{~mm}$. Preoperative symptoms, signs and urodynamic test results were collected and compared with surgical outcomes determined by clinical notes and postoperative urodynamics reports. Abnormal findings on presentation were categorized as dermatologic, urologic, orthopedic and neurologic. Results: Patient age ranged from 7 months to 17 years, and 12 were female. Sixteen (73\%) pa-
\end{abstract}

tients experienced subjective and/or objective improvement following surgical untethering. Fourteen patients had abnormal preoperative urodynamic testing, of which 12 underwent postoperative urodynamic testing. Five of these 12 (42\%) demonstrated objective improvement postoperatively. Patients presenting with abnormal findings in at least 2 categories were more likely to improve following untethering (88\%) than those with abnormalities in only 1 category (20\%; $p=0.009)$. Conclusion: Spinal cord untethering is a treatment option for occult tight filum terminale syndrome. Further evaluation of the relationship between preoperative findings and surgical outcomes may facilitate the selection of surgical candidates.

Copyright $\odot 2009$ S. Karger AG, Basel

\section{Introduction}

Tethered cord syndrome is a commonly encountered condition characterized by progressive motor and sensory changes in the legs, back and leg pain, orthopedic foot deformities, scoliosis and/or urinary dysfunction

Presented in part at the AANS/CNS Section on Pediatric Neurological Surgery 2007 Annual Meeting, Miami, Fla., November 26 to December 1, 2007.

\section{KARGER}

Fax +4161306 1234

E-Mail karger@karger.ch

www.karger.com
(C) 2009 S. Karger AG, Basel

$1016-2291 / 09 / 0454-0256 \$ 26.00 / 0$

Accessible online at:

www.karger.com/pne
Curtis J. Rozzelle, MD

Children's Hospital of Alabama

1600 7th Avenue South, ACC 400

Birmingham, AL 35233 (USA)

E-Mail curtis.rozzelle@ccc.uab.edu 
caused by traction on the lower portion of the spinal cord [1]. The diagnosis of a tethered cord can be confirmed by lumbosacral magnetic resonance imaging (MRI) that documents an abnormally low conus medullaris or a thickened filum terminale. Surgical untethering by sectioning the filum terminale can prevent symptom progression and often results in symptom improvement [2].

Occult tight filum terminale syndrome is the clinical condition in which the symptoms of spinal cord traction occur in conjunction with nondiagnostic lumbosacral MRI findings. The indications for sectioning the filum terminale in this situation are not well characterized and remain controversial. Several recent studies have reported a benefit to filum sectioning in occult tight filum terminale syndrome [3-6]. Patient selection seems to play a major role in the achievement of successful surgical outcomes in this clinical entity.

We conducted a study to evaluate preoperative clinical signs and symptoms in a cohort of patients undergoing surgical untethering for suspected occult tight filum terminale syndrome to assess any preoperative factors that might correlate with improvement following surgical untethering. Knowledge of the relationship between clinical presentation and surgical outcome may help to select suitable surgical candidates.

\section{Methods}

A retrospective review of all untethering procedures performed at the Women and Children's Hospital of Buffalo between April 1, 2004, and March 31, 2007, was undertaken. The study was approved by the hospital's institutional review board. The hospital records for all patients undergoing surgical untethering were reviewed, and those undergoing the procedure for suspected occult tight filum terminale syndrome were identified. Patients were given this diagnosis if they had clinical findings suggestive of spinal cord traction, a nondiagnostic lumbosacral MRI study and no other identifiable cause for tethering, such as a neoplasm or previous spinal surgery. A nondiagnostic MRI study was defined as a study in which the conus medullaris was above the $\mathrm{L}_{3}$ vertebral body and the filum terminale was less than $2 \mathrm{~mm}$ in thickness (fig. 1). Vertebral body level was determined by a 'countdown' from the $\mathrm{C}_{2}$ vertebral body. All magnetic resonance images were reviewed by a neuroradiologist and a pediatric neurosurgeon. Patients with a history of myelomeningocele repair or other previous untethering procedures were excluded from the study.

Clinical notes for patients undergoing surgical untethering for suspected occult tight filum terminale syndrome were then retrospectively reviewed. This data was evaluated for preoperative clinical signs or symptoms in each of the following 4 categories: dermatologic, urologic, orthopedic and neurologic (table 1). Pos-

itive dermatologic findings were an abnormal gluteal cleft, a lumbosacral dimple or a hemangioma. Positive orthopedic findings were asymmetric legs, feet or muscles, leg length discrepancy, calf asymmetry or scoliosis. Positive urologic findings were abnormal urodynamics, incontinence (urinary or fecal), urinary frequency, urgency or retention. Positive neurologic findings were back and/ or leg pain, decreased lower extremity strength, lower extremity paresthesias, decreased lower part of perineal sensation or abnormal gait. Patients were considered to have a positive finding from a category when at least 1 sign or symptom from that category was present. In those patients in whom preoperative urodynamic testing was performed, the urodynamics reports were evaluated for notations of encopresis and vesicoureteral reflux.

Patients included in the study underwent a standard surgical lysis of the filum terminale through a single-level laminoplasty. Intraoperative neuromonitoring was not used. A cut portion of the filum terminale was sent for pathologic review. Clinical assessment was performed postoperatively to determine whether any improvement in symptoms and/or signs occurred. Urodynamics were routinely recommended at 3 months postoperatively in those patients who had had abnormal preoperative urodynamics. Postoperative urodynamic test results were compared with preoperative ones, when available.

Two-way contingency table analysis was performed to determine the effectiveness of preoperative abnormalities from 1 of the 

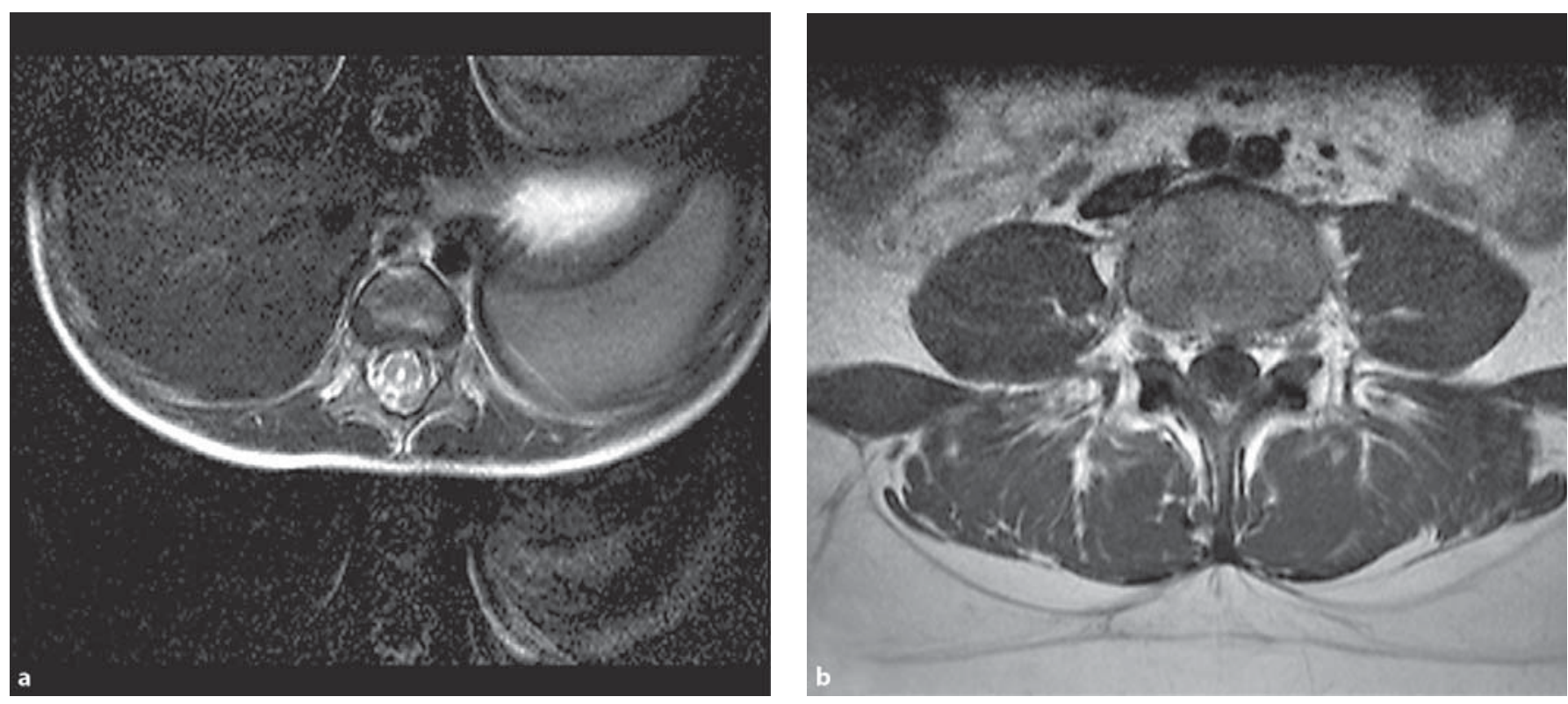

Fig. 2. Representative lumbosacral magnetic resonance images of patients included in the study. a $T_{2}$-weighted axial image of a patient with a small terminal syrinx adjacent to the $\mathrm{T}_{11}$ level. $\mathbf{b} \mathrm{T}_{1}$-weighted axial image in which a minimal amount of fatty infiltration is seen in the filum terminale.

Table 1. The 4 categories of clinical findings

Dermatologic (any of the following)

Abnormal gluteal cleft

Lumbosacral dimple

Hemangioma

Orthopedic (any of the following)

Asymmetric feet

Leg length discrepancy

Calf asymmetry

Scoliosis

Urologic (any of the following)

Abnormal urodynamics

Incontinence

Frequency

Urgency

Urinary retention

Neurologic (any of the following)

Back and/or leg pain

Decreased strength

Paresthesias

Decreased sensation

Abnormal gait

designated 4 categories (dermatologic, urologic, orthopedic or neurologic) or groups of these categories in predicting a benefit from surgical untethering. A similar analysis was performed to determine the likelihood that a patient with abnormal urodynamics would benefit from surgical untethering.
Table 2. Patient demographics

Ten of 22 male

Average age: 7.8 years

Conus above the $\mathrm{L}_{1-2}$ disk space: 9 patients

Conus between the $\mathrm{L}_{1-2}$ disk space and $\mathrm{L}_{3}$ vertebral body:

13 patients

Average follow-up: 15.9 months

\section{Results}

Eighty-two pediatric patients underwent untethering procedures by 2 pediatric neurosurgeons (V.L. and C.J.R.) during the time period reviewed. Sixty patients were excluded from review as they did not meet the specified criteria. Twenty-two patients underwent surgical untethering for suspected occult tight filum terminale syndrome (table 2). Among these patients, 10 were males, and the average age was 7.8 years (range 7 months to 17 years). The average duration of postoperative follow-up was 15.9 months (range 5-31 months).

All 22 patients had nondiagnostic lumbosacral MRI. Of these, 2 patients had a small terminal syrinx and 5 patients had a minimal amount of filum terminale fatty infiltration on lumbosacral MRI (fig. 2). Conus medullaris 
Table 3. Results

\begin{tabular}{|c|c|c|c|}
\hline Sex, age & $\begin{array}{l}\text { Preoperative } \\
\text { symptom categories }\end{array}$ & $\begin{array}{l}\text { Conus level/MRI } \\
\text { findings }\end{array}$ & Postoperative improvements \\
\hline Female, 2 years & $\mathrm{N}, \mathrm{U}$ & inferior $\mathrm{L}_{2}$ & objective and subjective \\
\hline Male, 16 years & $\mathrm{O}, \mathrm{U}$ & inferior $\mathrm{L}_{2}$ & objective and subjective \\
\hline Female, 7 months & $\mathrm{D}, \mathrm{N}$ & inferior $\mathrm{L}_{1}$ & objective and subjective \\
\hline Female, 17 years & $\mathrm{N}$ & $\operatorname{mid} \mathrm{L}_{2}, \mathrm{MFI}$ & none \\
\hline Female, 2 years & $\mathrm{U}$ & $\operatorname{mid} \mathrm{L}_{2}, \mathrm{MFI}$ & none \\
\hline Female, 11 years & $\mathrm{D}, \mathrm{U}, \mathrm{O}$ & $\mathrm{L}_{2-3}$ & subjective \\
\hline Male, 14 years & $\mathrm{D}, \mathrm{N}, \mathrm{O}, \mathrm{U}$ & $\mathrm{T}_{12}-\mathrm{L}_{1}$ & objective and subjective \\
\hline Female, 4 years & $\mathrm{N}, \mathrm{U}$ & inferior $\mathrm{L}_{2}$ & none \\
\hline Male, 10 years & $\mathrm{D}, \mathrm{N}, \mathrm{O}, \mathrm{U}$ & $\mathrm{L}_{1-2}$ & objective and subjective \\
\hline Female, 12 years & $\mathrm{N}, \mathrm{O}, \mathrm{U}$ & inferior $\mathrm{L}_{2}$ & none \\
\hline Female, 8 years & $\mathrm{N}, \mathrm{U}$ & $\mathrm{T}_{12}-\mathrm{L}_{1}$ & none \\
\hline Female, 15 years & $\mathrm{D}, \mathrm{N}, \mathrm{U}$ & $\mathrm{L}_{1-2}, \mathrm{MFI}$ & objective and subjective \\
\hline Male, 15 years & $\mathrm{D}, \mathrm{O}, \mathrm{U}$ & mid $L_{1}$, syrinx & objective and subjective \\
\hline Female, 7 years & $\mathrm{N}, \mathrm{O}, \mathrm{U}$ & inferior $\mathrm{L}_{2}, \mathrm{MFI}$ & objective and subjective \\
\hline Female, 3 years & $\mathrm{N}, \mathrm{U}$ & $\operatorname{mid} \mathrm{L}_{2}$, syrinx & objective and subjective \\
\hline Male, 1 year & $\mathrm{D}$ & $\mathrm{L}_{2-3}$ & none \\
\hline Male, 6 years & $\mathrm{D}, \mathrm{U}$ & $\mathrm{L}_{2-3}$ & subjective \\
\hline Male, 7 years & $\mathrm{D}, \mathrm{U}$ & $\operatorname{mid} \mathrm{L}_{2}$ & objective and subjective \\
\hline Female, 7 years & $\mathrm{N}, \mathrm{U}$ & $\mathrm{L}_{1-2}$ & objective and subjective \\
\hline Male, 11 years & $\mathrm{N}$ & inferior $\mathrm{L}_{2}$ & subjective \\
\hline Male, 3 years & $\mathrm{D}, \mathrm{N}$ & $\operatorname{mid} \mathrm{L}_{2}$ & subjective \\
\hline Male, 1 year & $\mathrm{N}$ & inferior $\mathrm{L}_{1}, \mathrm{MFI}$ & subjective \\
\hline
\end{tabular}

Table 4. Results summary

\begin{tabular}{lcl}
\hline $\begin{array}{l}\text { Number of categories (dermatologic, } \\
\text { urologic, orthopedic or neurologic) in } \\
\text { which patients had a preoperative finding }\end{array}$ & Patients & $\begin{array}{l}\text { Patients } \\
\text { improving } \\
\text { postoperatively }\end{array}$ \\
\hline 1 & 5 & $1(20 \%)$ \\
2 & 10 & $9(90 \%)$ \\
3 & 5 & $4(80 \%)$ \\
4 & 2 & $2(100 \%)$ \\
\hline
\end{tabular}

levels ranged from adjacent to the $\mathrm{T}_{12}-\mathrm{L}_{1}$ disk space to adjacent to the $\mathrm{L}_{2-3}$ disk space. The conus medullaris was superior to the $\mathrm{L}_{1-2}$ disk space in 9 patients and inferior to the $\mathrm{L}_{1-2}$ disk space, but above the $\mathrm{L}_{3}$ vertebral body in 13 patients (table 3 ). Five patients had preoperative signs or symptoms from only 1 of our designated clinical categories (dermatologic, orthopedic, urologic or neurologic). Seventeen patients had preoperative signs or symptoms from 2 or more of these categories.

Overall, 16 patients improved after surgical untethering, 4 patients experienced no change in their preopera-
Table 5. Patient improvement

\begin{tabular}{lll}
\hline & $\begin{array}{l}\text { Subjective } \\
\text { only }\end{array}$ & $\begin{array}{l}\text { Subjective } \\
\text { and objective }\end{array}$ \\
\hline $\begin{array}{l}\text { Patients with postoperative } \\
\text { improvements }\end{array}$ & $5 / 16(31 \%)$ & $11 / 16(69 \%)$ \\
\hline
\end{tabular}

tive symptoms, and 2 patients reported symptom progression after surgery (table 4 ). Of the patients demonstrating improvement, 5 of 16 (31\%) had only subjective improvement, and 11 (69\%) had both subjective and objective improvement (table 5). Objective improvement was defined as the improvement of a previous neurologic examination finding, improved bladder control, or improved urodynamic test results. Improvement after surgical untethering correlated with the number of designated clinical categories in which a patient had positive preoperative findings. Two of 2 patients with preopera- 
tive findings in 4 categories had improvement postoperatively; 4 of 5 with preoperative findings in any 3 categories improved; 9 of 10 with preoperative findings in any 2 categories improved, and 1 of 5 with preoperative findings in any 1 category improved $\left(\chi^{2}=9.40, p=0.024\right)$. Patients presenting with abnormal findings in at least 2 categories were more likely to improve after untethering than those with preoperative abnormalities in only 1 category (from 88 to $20 \%, \mathrm{p}=0.009$ ).

Twenty-one patients underwent preoperative urodynamic testing. One patient with back pain, scoliosis, leg length discrepancy and a lumbosacral dimple did not undergo preoperative urodynamics. Of these 21 patients, 14 had abnormal results, 6 had normal results, and, in 1 patient, the results were inconclusive. Twelve of 14 patients with abnormal preoperative urodynamics also underwent postoperative urodynamic testing. Two patients with abnormal preoperative urodynamics did not undergo postoperative testing due to patient or parent refusal. Five of $12(42 \%)$ patients with abnormal preoperative urodynamic testing demonstrated objective postoperative improvement.

There was no surgical mortality or neurologic morbidity. There was 1 cerebrospinal fluid leak and 1 wound infection. Neither the level of the conus medullaris ( $\mathrm{p}=$ 0.65 ), the presence of a minimal amount of filum terminale fatty infiltration $(\mathrm{p}=0.56)$ nor the presence of a spinal cord syrinx $(\mathrm{p}=0.36)$ correlated with postoperative outcome. In all cases, cauterized connective tissue was found during surgical pathology review of the cut filum sections (patients with other surgical pathology findings had been previously excluded from the study).

\section{Discussion}

The present study is a retrospective analysis of preoperative predictors for improvement following surgical untethering in occult tight filum terminale syndrome. Patients were given this diagnosis if they had clinical signs or symptoms felt to be attributable to spinal cord traction and a lumbosacral MRI study in which the conus medullaris was superior to the $\mathrm{L}_{3}$ vertebral body and the filum terminale was less than $2 \mathrm{~mm}$ in thickness. Each patient was evaluated for the presence or absence of preoperative findings in each of 4 categories: dermatologic, urologic, orthopedic and neurologic. Patients with preoperative findings in more than 1 category were found to be more likely to have clinical improvement after surgical untethering than those with preoperative findings in only 1 category. Of the patients demonstrating improvement postoperatively, $69 \%$ had objective improvement (11 of 16). Postoperative improvement did not correlate with preoperative conus medullaris level or with other imaging findings.

Yamada et al. [1] described the pathophysiology of the tethered cord syndrome due to stretch-induced spinal cord dysfunction in their landmark paper. When traction is applied to the lumbosacral cord, mitochondrial oxidative metabolism is impaired secondary to microcirculatory ischemia leading to neuronal dysfunction [1]. A given patient's spinal cord could potentially be subjected to pathologic traction without abnormal inferior displacement of the conus medullaris $[7,8]$, and this is the basis for the proposed occult tight filum terminale syndrome.

Surgical untethering may prevent further neurologic deterioration and result in symptom improvement in this condition as it does for the tethered cord syndrome. However, the indications for surgical untethering in occult tight filum terminale syndrome remain controversial [914]. Several retrospective reports suggest a clinical benefit to surgical release in occult tight filum syndrome; however, many of these studies are observational and rely on patient reporting as a primary outcome measure $[6$, $11,15]$. Critics cite an unknown natural history of occult tight filum syndrome and the absence of prospective data to argue against surgical release in these cases [10]. It remains unclear which patient population, if any, is most likely to benefit from surgical lysis in occult tight filum syndrome.

For the purpose of this study, a conus medullaris at or below the $\mathrm{L}_{3}$ vertebral body was considered abnormally low and a conus medullaris above the $\mathrm{L}_{3}$ vertebral body was considered nondiagnostic for the tethered cord syndrome. Reports on the expected spinal level of the normal conus medullaris vary, and a conus medullaris at the $\mathrm{L}_{2-3}$ disk space would be considered normal by some authors and low by others $[16,17]$. We chose a more inferior level to define a normal conus level in an attempt to include all patients for whom there is diagnostic uncertainty and the potential diagnosis of occult tight filum syndrome. The risk of choosing a more inferior conus level is the introduction of a spectrum bias. Although this is a possibility, it should be noted that conus medullaris level did not correlate with outcome in this study.

Many of the symptoms of spinal cord traction, such as pain and paresthesias, are subjective, which can make accurate diagnosis more challenging, particularly in cases where available imaging studies are nondiagnostic. Thus, clinical signs and symptoms are paramount in the diag- 
nosis of occult tight filum syndrome. In the present study, those patients with multiple preoperative findings that could be attributed to spinal cord traction were more likely to improve after surgical untethering than those with preoperative findings in only 1 of our designated categories. Urodynamic testing provides an objective measure in evaluating this patient population, and postoperative urodynamic testing was performed in several cases in this series. It is possible that those patients who did not improve after surgical untethering represent a class of patients misdiagnosed to have occult tight filum terminale syndrome. However, this possibility is tempered by the knowledge that not all patients with overt tethered cord syndrome improve after surgical untethering.

\section{Conclusions}

Surgical indications for occult tight filum terminale syndrome remain a controversial topic. Those patients with preoperative findings in multiple clinical categories may be more likely to benefit from surgical untethering in occult tight filum terminale syndrome. Further investigation of this topic is warranted.

\section{Acknowledgments}

We thank Paul H. Dressel, BFA, for assistance with the preparation of the illustrations and Debra J. Zimmer, AAS CMA-A, for editorial assistance.

\section{References}

1 Yamada S, Zinke DE, Sanders D: Pathophysiology of 'tethered cord syndrome'. J Neurosurg 1981;54:494-503.

2 McLone DB, Naidich TP: The tethered spinal cord; in McLaurin RL, Venes JL, Schut L, Epstein F (eds): Pediatric Neurosurgery: Surgery of the Developing Nervous System, ed 2. Philadelphia, Saunders Co., 1989, pp 71-96.

$\checkmark 3$ Komagata M, Endo K, Nishiyama M, Ikegami H, Imakiire A: Management of tight filum terminale. Minim Invasive Neurosurg 2004;47:49-53.

-4 Metcalfe PD, Luerssen TG, King SJ, Kaefer M, Meldrum KK, Cain MP, Rink RC, Casale AJ: Treatment of the occult tethered spinal cord for neuropathic bladder: results of sectioning the filum terminale. J Urol 2006;176: 1826-1830.

5 Selcuki M, Unlu A, Ugur HC, Soygur T, Arikan N, Selcuki D: Patients with urinary incontinence often benefit from surgical detethering of tight filum terminale. Childs Nerv Syst 2000;16:150-155.
6 Wehby MC, O’Hollaren PS, Abtin K, Hume JL, Richards BJ: Occult tight filum terminale syndrome: results of surgical untethering. Pediatr Neurosurg 2004;40:51-58.

7 Tubbs RS, Oakes WJ: Can the conus medullaris in normal position be tethered? Neurol Res 2004;26:727-731.

$\checkmark 8$ Warder DE, Oakes WJ: Tethered cord syndrome and the conus in a normal position. Neurosurgery 1993;33:374-378.

$\checkmark 9$ Albright AL: Occult tight filum terminale syndrome: results of surgical untethering (letter to the editor). Pediatr Neurosurg 2005;41:58.

10 Drake JM: Occult tethered cord syndrome: not an indication for surgery. J Neurosurg 2006;104:305-308.

$>11$ Selden NR: Occult tethered cord syndrome: the case for surgery. J Neurosurg 2006;104: 302-304.
12 Selden N, Steinbok P, Gupta N, Drake J, Garton $\mathrm{H}$ : Response to Yamada. J Neurosurg Pediatr 2007; 106:411-414.

13 Steinbok P, Garton HJ, Gupta N: Occult tethered cord syndrome: a survey of practice patterns. J Neurosurg 2006;104:309-313.

$\checkmark 14$ Wehby MC, O’Hollaren PS: Response to Dr. Albright's letter to the editor. Pediatr Neurosurg 2005;41:59-60.

- 15 Nazar GB, Casale AJ, Roberts JG, Linden RD: Occult filum terminale syndrome. Pediatr Neurosurg 1995;23:228-235.

$>16$ Kesler H, Dias MS, Kalapos P: Termination of the normal conus medullaris in children: a whole-spine magnetic resonance imaging study. Neurosurg Focus 2007;23:1-5.

$\checkmark 17$ Wilson DA, Prince JR: MR imaging determination of the location of the normal conus medullaris throughout childhood (John Caffey Award). AJR Am J Roentgenol 1989; 152:1029-1032. 